\title{
Coordinative Self-Assembly and Solution-Phase X-ray Structural Characterization of Cavity-Tailored Porphyrin Boxes
}

\author{
Suk Joong Lee, ${ }^{\dagger}$ Karen L. Mulfort, ${ }^{\dagger}, \ddagger$ Xiaobing Zuo, ${ }^{\ddagger}$ Andrew J. Goshe, ${ }^{\ddagger}$ Paul J. Wesson,, \\ SonBinh T. Nguyen, ${ }^{\dagger}$ Joseph T. Hupp, ${ }^{*}, \dagger$ and David M. Tiede ${ }^{\ddagger}$ \\ Departments of Chemistry and Chemical and Biological Engineering, Northwestern University, \\ Evanston, Illinois 60208, and Chemistry Division, Argonne National Laboratory, Argonne, Illinois 60439
}

Received October 4, 2007; E-mail: j-hupp@northwestern.edu

The challenge of building functional, hollow, metal-linked supramolecules that can begin to mimic the remarkable behavior of clefts, cavities, and pores in enzymes and zeolites has attracted tremendous attention from the coordination chemistry community. ${ }^{1}$ Reversible ligation, together with well-defined local metal coordination motifs, often allows for one-pot assembly of supramolecules of predetermined architecture in high or even quantitative synthetic yield. Among the many interesting architectures described (including triangles, ${ }^{2}$ rectangles,${ }^{3}$ higher polygons,${ }^{4}$ and various polyhe$\mathrm{dra}^{5}$ ), squares ${ }^{6}$ are particularly ubiquitous, as the required $90^{\circ}$ bond angles are easily generated based on octahedral or square-planar metal coordination. We have explored in some detail the synthetic and functional chemistry of "molecular squares" featuring porphyrins as edges ${ }^{7}$ and $\operatorname{Re}(\mathrm{CO})_{3} \mathrm{Cl}$ units as corners. ${ }^{8}$ We find that the nanometer-sized cavities defined by the squares can be chemically functionalized or exploited directly for sensing ${ }^{8 b, e}$ or enzyme-like catalysis. ${ }^{8 \mathrm{~d}}$ Additionally, we find that aggregates of porphyrinic squares can be configured as thin films or membranes and used as tunable molecular filters ${ }^{8 \mathrm{a}, \mathrm{c}, \mathrm{f}, \mathrm{h}}$ or as porous chromophoric coatings for light-to-electrical energy conversion. ${ }^{8 \mathrm{~g}, \mathrm{i}, \mathrm{j}}$ While the observed functional behavior is promising, the selectivity attained in both catalysis $^{8 \mathrm{~d}}$ and molecular sieving ${ }^{8 \mathrm{~h}}$ is less than expected based on ideal box-like geometries. Computational ${ }^{9}$ and experimental studies $^{8, \mathrm{i}, 10}$ reveal two problems: torsional motion along the metalporphyrin-metal axis and ambiguous outside versus inside functionalization (via axial ligation of available $\mathrm{Zn}$ (II) sites) (Scheme 1). We reasoned that the torsional problem could be most simply overcome by assembling double-square ("box kite") structures (Scheme 2). ${ }^{11}$ Unfortunately, our attempts to construct box kites were thwarted by unacceptably slow conversion of "wrong" kinetic products to the presumably thermodynamically preferred doublesquare (octarhenium) structure. In retrospect, this is not altogether surprising as simple single-square (tetrarhenium) compounds are typically obtained in high yield only after 2 days of reaction at reflux.

We now report that by resorting to weaker interactions $(\mathrm{Zn}-$ $\mathrm{N}$ (imine) versus $\mathrm{Re}-\mathrm{N}($ imine $)$ ) and a different binding motif, large, well-defined, torsionally constrained porphyrin boxes can easily and rapidly be formed. Additionally, by enlisting $\mathrm{Sn}(\mathrm{IV})$ as a doubly functional axial coordination site, the problem of inside versus outside cavity modification can be circumvented. Furthermore, as detailed below, we find that the use of sterically demanding cavitymodifying ligands produces an unusual twisted box, while the use of ligand mixtures engenders steric self-sorting and produces a multi-porphyrin box containing an unusual unsymmetrical cavity. As illustrated in Scheme 3 (and supported experimentally as described below), two pyridine-derivatized porphyrin dimers, A,

\footnotetext{
$\dagger$ Department of Chemistry, Northwestern University.

Argonne National Laboratory.

$\S$ Department of Chemical and Biological Engineering.
}

\section{Scheme 1}

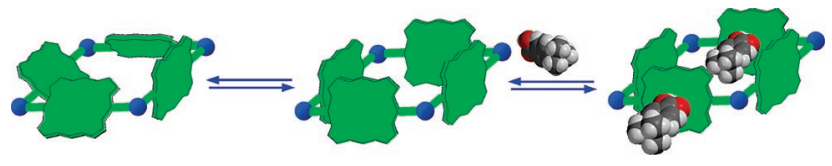

Scheme 2

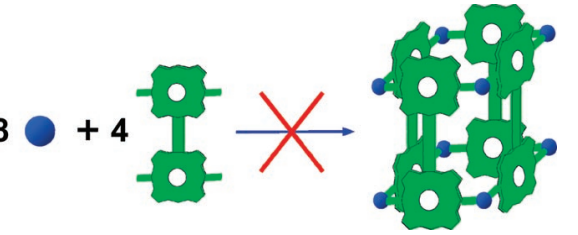

Scheme 3

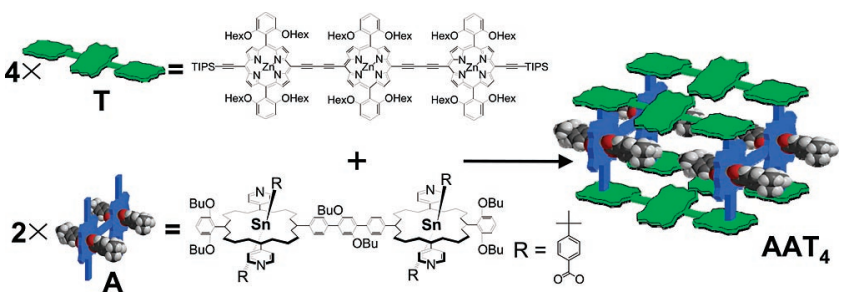

when combined with four porphyrins trimers, $\mathbf{T}$, generate a symmetrical 16-porphyrin box, $\mathbf{A} \mathbf{A} \mathbf{T}_{\mathbf{4}}$. Chemically orthogonal metalation of $\mathbf{A}$ with $\mathrm{Sn}(\mathrm{IV})$ and $\mathbf{T}$ with $\mathrm{Zn}(\mathrm{II})$ ensures that selfrecognition (A with $\mathbf{A}, \mathbf{T}$ with $\mathbf{T}$ ) is avoided. Torsional motion along the $\mathrm{Zn}-$ porphyrin- $\mathrm{Zn}$ axis is eliminated by tethering each A to a total of four zincs. Redundant axial ligation functionalization of $\mathrm{Sn}(\mathrm{IV})$ sites (with tert-butyl benzoate) ensures that four cavitymodifying ligands are directed inward. Additionally, the steric demand created by the ligands forces the $\mathbf{A}$ units to link selectively the first and third porphyrins of the $\mathbf{T}$ units, leaving the central $\mathrm{Zn}$ sites unoccupied, thereby defining an unusually large cavity $(22 \times$ $14 \times 10 \AA$ A). Shown in Figure 1 is a series of electronic absorption spectra for the addition of $\mathbf{A}$ to $\mathbf{T}$ in toluene as solvent. The observed binding stoichiometry (see inset) is consistent with the rapid formation of the proposed $\mathbf{A} \mathbf{A} \mathbf{T}_{\mathbf{4}}$ box, while the observed isosbestic behavior implies "all-or-nothing" box formation (i.e., negligible buildup of partially formed boxes at intermediate points in the titration). The spectra, which are dominated by $\mathbf{T}$ species, are marked by broadening of Soret bands (blue bands) and shifts of $\mathrm{Q}$ bands (red bands) to longer wavelength. On the basis of previous studies of similar species, ${ }^{11}$ the spectral changes point to partial planarization of the otherwise torsionally labile trimer units.

Figure 2 shows ${ }^{1} \mathrm{H}$ NMR spectra for free $\mathbf{A}$, free $\mathbf{T}$, and the proposed 16-porphyrin box, $\mathbf{A} \mathbf{A} \mathbf{T}_{\mathbf{4}}$. Detailed assignments (together with syntheses and further characterization of $\mathbf{A}$ and $\mathbf{T}$ ) are presented as Supporting Information (SI). Briefly, however, comparison of resonances due to the $\alpha$ and $\beta$ protons of the pyridyl 


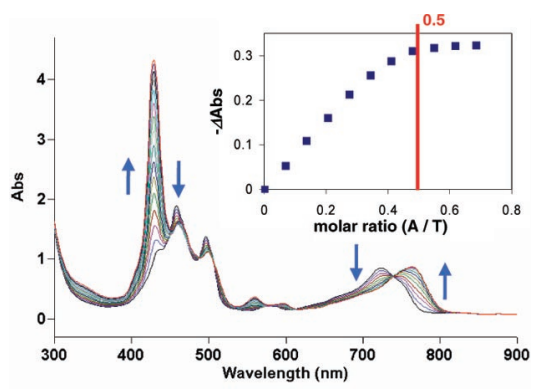

Figure 1. Electronic absorption spectra for the addition of $\mathbf{A}$ to $\mathbf{T}$ in toluene at $1.24 \times 10^{-5} \mathrm{M}$. Inset: absorbance change at $458 \mathrm{~nm}$, showing stoichiometric coordination of $\mathbf{A}$

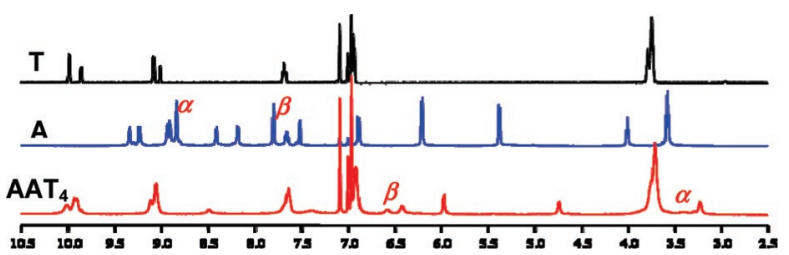

Figure 2. ${ }^{1} \mathrm{H}$ NMR spectra of $\mathbf{T}, \mathbf{A}$, and the $\mathbf{A A T}_{4}$ box in toluene- $d_{8}$.

Table 1. Self-Diffusivities and Hydrodynamic Radii at $25^{\circ} \mathrm{C}$ in Toluene

\begin{tabular}{lcc}
\hline & $\begin{array}{c}\text { self-diffusivity } \\
\left(\mathrm{cm}^{2} / \mathrm{s}\right)\end{array}$ & $\begin{array}{c}\text { hydrodynamic } \\
\text { radii }(\AA)\end{array}$ \\
\hline $\mathbf{T}$ & $(1.39 \pm 0.08) \times 10^{-6}$ & $28 \pm 2$ \\
$\mathbf{A}$ & $(1.84 \pm 0.04) \times 10^{-6}$ & $21 \pm 1$ \\
$\mathbf{B}$ & $(1.26 \pm 0.10) \times 10^{-6}$ & $30 \pm 2$ \\
$\mathbf{A A T}_{\mathbf{4}}$ & $(1.19 \pm 0.10) \times 10^{-6}$ & $32 \pm 3$ \\
$\mathbf{A B T}_{\mathbf{4}}$ & $(1.01 \pm 0.09) \times 10^{-6}$ & $38 \pm 3$ \\
$\mathbf{B B T}_{\mathbf{4}}$ & $(0.81 \pm 0.04) \times 10^{-6}$ & $48 \pm 2$ \\
$\mathbf{L}_{\mathbf{b}} \mathbf{L}_{\mathbf{b}} \mathbf{L}_{\mathbf{b}} \mathbf{T}_{\mathbf{4}}{ }^{a}$ & $(1.51 \pm 0.21) \times 10^{-6}$ & $34 \pm 4$ \\
\hline
\end{tabular}

${ }^{a}$ Taken in $\mathrm{CD}_{2} \mathrm{Cl}_{2} ; \mathrm{L}_{\mathrm{b}}=$ free base version of $\mathbf{A}$ and $\mathbf{B}$

rings of A display tremendous downfield shifts: $\Delta d=5.43$ and $=$ 1.21 , consistent with the coordination of the pyridyl group to $\mathrm{Zn}$ centers embedded in the highly conjugated trimer units. ${ }^{12}$ Notably, other $\mathbf{A}$ aromatic resonances are also shifted.Pulsed field gradient (PFG) NMR measurements revealed that $\mathbf{A} \mathbf{A} \mathbf{T}_{\mathbf{4}}$ diffuses less rapidly than either $\mathbf{A}$ or $\mathbf{T}$, implying a larger hydrodynamic radius for the box than for its components (Table 1). More importantly, the PFGNMR measurements show that all $\mathbf{A} \mathbf{A} \mathbf{T}_{\mathbf{4}}$ protons diffuse at the same rate-implying that all belong to the same object. That only a single object is formed is consistent with rapid equilibration to form the thermodynamically most stable assembly. Notably, because of the intentional mismatch in distance between $\mathrm{Zn}$ sites on $\mathbf{T}$ versus pendant pyridines on $\mathbf{A}$, the smallest closed structure (fully zincligated structure) that can be formed from $\mathbf{A}$ and $\mathbf{T}$ without strain is the orthogonally arranged assembly, $\mathbf{A A T}_{\mathbf{4}}$. Enthalpy optimization, of course, favors the formation of fully ligated structures, while entropy favors the formation of the smallest such structures.To complete the initial characterization of the proposed box assembly, we turned to solution-phase small-angle X-ray scattering (SAXS). As we have recently shown for other supramolecular assemblies, solution-phase X-ray measurements are extraordinarily useful for characterizing assemblies whose structures and sizes cannot easily be determined by traditional crystallographic and/or mass spec methods. ${ }^{13,14}$ By application of the Guinier analysis to scattering data collected at very low angles, the electron-density-weighted radius of gyration $\left(R_{\mathrm{g}}\right)$ of the molecular or supramolecular scatterer can be determined. ${ }^{14}$ The resulting values can then be compared to those calculated for candidate structures. The Guinier eq 1 relates $q$-dependent (reciprocal-space-dependent) scattering intensities to
$R_{\mathrm{g}}$, where $I(0)$ is proportional to the electron-density-weighted square of the number of electrons in the scatterer:

$$
I(q)=I(0) \exp \left(-q^{2} R_{\mathrm{g}}^{2} / 3\right)
$$

Figure 3 presents solvent-subtracted plots of $\log$ (intensity) against $q^{2}$ for submillimolar solutions of $\mathbf{A A T}_{\mathbf{4}}$ and $\mathbf{T}$. The linearity of the plots confirms that only a single assembly is present at detectable concentration in each solution; that is, aggregates, dissociated structures, and competing structures are absent. Quantitative analysis yields $20.7 \pm 0.3 \AA$ for $R_{\mathrm{g}}$, in essentially perfect agreement with the calculated value for $\mathbf{A A} \mathbf{T}_{\mathbf{4}}$ (20.6 $\AA$; Table 2). Notably, because of the electron-density weighting (which favors metal ions and discounts hydrogen atoms), $R_{\mathrm{g}}$ is both expected and observed to be considerably smaller than either the apparent hydrodynamic radius (Table 1) or an assembly encompassing radius. We hypothesized that the assembly chemistry might be extendable to openoligomer structures if the steric demands of the cavity-modifying carboxylate ligands were sufficiently great (Scheme 4). Toward this end, we prepared several variants of the dimeric $\mathbf{A}$ unit - the most sterically extreme version featuring $3^{\prime}, 5^{\prime}$-di(4-tert-butylphenyl)biphenyl-4-carboxylates as axial ligands. Models showed that this version (termed $\mathbf{B}$ ) is sterically incapable of combining with $\mathbf{T}$ to produce a porphyrin box having the architecture of $\mathbf{A A T}_{\mathbf{4}}$. UVvis titration of $\mathbf{T}$ with $\mathbf{B}$, however, unexpectedly revealed isosbestic behavior and a $\mathbf{T}: \mathbf{B}$ stoichiometry of 2:1-like that for titration of

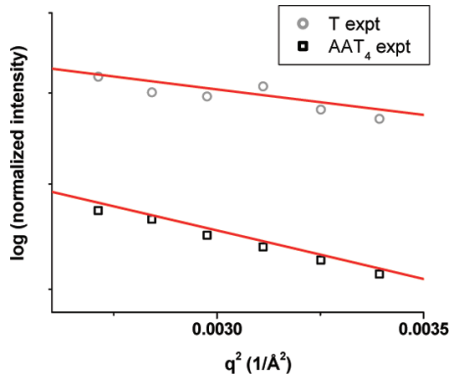

Figure 3. Guinier plots for small-angle X-ray scattering by $\mathbf{A A T}_{\mathbf{4}}$ and $\mathbf{T}$. The slopes of the plots scale as $R_{\mathrm{g}}{ }^{2}$, indicating a larger radius of gyration for $\mathbf{A A T} \mathbf{T}_{\mathbf{4}}$ than for $\mathbf{T}$. Symbols represent experimental data points; lines represent Guinier analysis of modeled scattering.

Table 2. Comparison of Modeled and Experimentally Obtained $R_{g}$ Values for $\mathbf{T}$ and the Box Assemblies

\begin{tabular}{lll}
\hline & & \multicolumn{1}{c}{$R_{\mathrm{g}}(\AA)$} \\
\hline $\mathbf{T}$ & model & 14.8 \\
& experiment & $15.1 \pm 0.4$ \\
$\mathbf{A A T}_{4}$ & model & 20.6 \\
& experiment & $20.7 \pm 0.3$ \\
$\mathbf{A B T}_{\mathbf{4}}$ & model & 20.7 \\
& experiment & $20.9 \pm 0.4$ \\
$\mathbf{B B T}_{4}$ & model & 20.1 \\
& experiment & $20.8 \pm 0.4$ \\
\hline
\end{tabular}

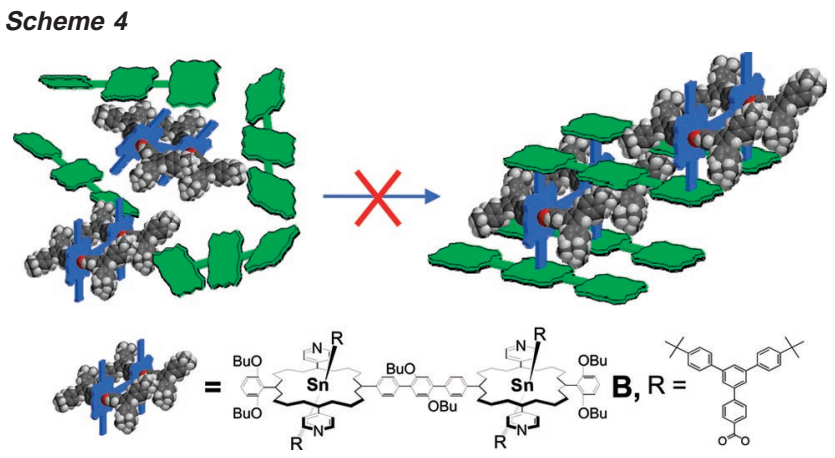


T with A. NMR experiments yielded similar shifts as seen with A, implying that the pyridyl groups of $\mathbf{B}$ likewise attached themselves to $\mathrm{Zn}$ (II). To our further surprise, PFG-NMR measurements showed that only a single species was formed, albeit larger than $\mathbf{A A T}_{4}$ (Table 1). SAXS measurements confirmed the monodispersity of the assembly, yielding $20.7 \pm 0.4 \AA$ for $R_{\mathrm{g}}$. Modeling eventually led us to consider the unusual twisted box structure $\left(\mathbf{B B T}_{4}\right)$ shown below (distances exaggerated to illustrate structure). While the model is speculative, its $R_{\mathrm{g}}(20.1 \AA)$ is in very good agreement with experiment. Evidently, the torsional strain introduced in $\mathbf{T}$ is less than the energy gained by forming a discrete closed box.

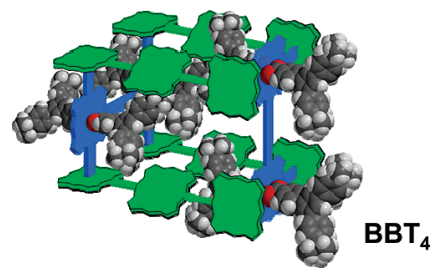

Finally, we examined a 4:1:1 combination of $\mathbf{T}$ with $\mathbf{A}$ and $\mathbf{B}$. PFG-NMR measurements yielded linear of plots $\ln$ [intensity] versus [gradient amplitude] ${ }^{2}$ (and essentially identical diffusion coefficients for all protons), showing that the solution contained a single assembly rather than a mixture of $\mathbf{A A} \mathbf{T}_{\mathbf{4}}$ and $\mathbf{B B T} \mathbf{T}_{\mathbf{4}}$. Furthermore, the apparent hydrodynamic radius ${ }^{15}$ of the new assembly proved to be intermediate between those of boxes $\mathbf{A A} \mathbf{T}_{\mathbf{4}}$ and $\mathbf{B B} \mathbf{T}_{\mathbf{4}}$ (Table 1). These results point to formation of a lower-symmetry box containing both A and $\mathbf{B}$ (Scheme 5). SAXS measurements (Table

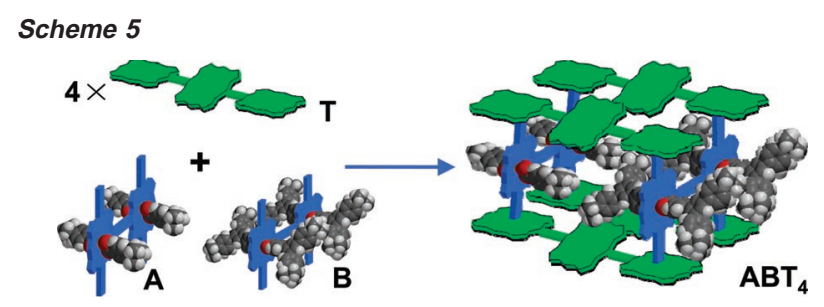

2, Figure S6) yielded a radius of gyration in excellent agreement with model calculations. The observed social self-sorting ${ }^{16}$ of $\mathbf{A}$ and $\mathbf{B}$ to form $\mathbf{A B} \mathbf{T}_{\mathbf{4}}$, to the exclusion of $\mathbf{A} \mathbf{A} \mathbf{T}_{\mathbf{4}}$ and $\mathbf{B B} \mathbf{T}_{\mathbf{4}}$, is presumably driven by elimination of the strain associated with the twisted assembly, $\mathbf{B B T}_{\mathbf{4}}$.

To summarize, combining linear $\mathrm{Zn}$ porphyrin trimers with orthogonally derivatized porphyrin dimers leads rapidly and spontaneously to the formation of monodisperse, torsionally constrained boxes comprising six components and a total of 16 metalloporphyrins. The use of sterically demanding dimer subunits (B) produces an unusual twisted box. Adding $\mathbf{B}$ to preformed $\mathbf{A A} \mathbf{T}_{4}$ and excess $\mathbf{T}$ results in rapid social self-sorting to produce a lower symmetry box. In situ X-ray scattering measurements confirm the formation of monodisperse assemblies of precisely the size expected from model box structures. As we will show elsewhere, the precise cavity-tailoring capability implied by the formation of the new boxes can be exploited for both size-selective and enantioselective catalysis.

Acknowledgment. We gratefully acknowledge the Basic Energy Sciences program, U.S. Department of Energy (Grant No. DEFG02-ER15244, Contract No. W-31-109-ENG-38), for initial support and AFOSR and DTRA via ARO for subsequent support. K.L.M. thanks Argonne for support as a Lab-Grad Fellow.

Supporting Information Available: Complete experimental details of syntheses, compound characterization, PFG-NMR and X-ray ex- perimental methods and data analysis. This material is available free of charge via the Internet at http://pubs.acs.org.

\section{References}

(1) (a) Leininger, S.; Olenyuk B.; Stang, P. J. Chem. Rev. 2000, 100, 853908. (b) Swiegers, G. F.; Malefetse, T. J. Chem. Rev. 2000, 100, 34833538. (c) Riley, D. D. Chem. Rev. 1999, 99, 2573-2588. (d) Fujita, M Chem. Soc. Rev. 1998, 27, 417-425. (e) Linton, B.; Hamilton, A. D. Chem. Rev. 1997, 97, 1669-1680. (f) Stang, P. J.; Olenyuk, B. Acc. Chem Res. 1997, 30, 502-518

(2) (a) Lee, S. J.; Hu, A.; Lin, W. J. Am. Chem. Soc. 2002, 124, 1294812949. (b) Schweiger, M.; Seidel, S. R.; Arif, A. M.; Stang, A. J. Inorg. Chem 2002, 41, 2556-2559. (c) Piotrowski, H.; Polborn, K.; Hilt, G; Severin, K. J. Am. Chem. Soc. 2001, 123, 2699-2700. (d) Navarro, A. J. R.; Lippert, B. Coord. Chem. Rev. 2001, 222, 219-250. (e) Sautter, A.; Schmid, D. G.; Jung, G.; Würthner, F. J. Am. Chem. Soc. 2001, 123, 5424-5430. (f) Cotton, F. A.; Lin, C.; Murillo, C. A. Inorg. Chem. 2001, 40, 575-577. (g) Burini, A.; Bravi, R.; Fackler Jr., J. P.; Galassi, R. Grant, T. A.; Omary, M. A.; Pietroni, B. R.; Staples, R. J. Inorg. Chem. 2000, 39, 3158-3165. (h) Cotton, F. A.; Daniels, L. M.; Lin, C.; Murillo, C. A. J. Am. Chem. Soc. 1999, 121, 4538-4539.

(3) (a) Manimaran, B.; Thanasekaran, P.; Rajendran, T.; Lin, R.-J.; Chang, I.-J.; Lee, G.-H.; Peng, S.-M.; Rajagopal, S.; Lu, K.-L. Inorg. Chem. 2002 41, 5323-5325. (b) Kuehl, C. J.; Huang, S. D.; Stang, P. J. J. Am. Chem. Soc. 2001, 123, 9634-9641.

(4) (a) Campos-Fernandez, C. S.; Clerac, R.; Koomen, J. M.; Russell, D. H.; Dunbar, K. R. J. Am. Chem. Soc. 2001, 123, 773-774. (b) MacDonnell, F. M.; Ali, M. M. J. Am. Chem. Soc. 2000, 122, 11527-11528. (c) Habicher, T.; Nierengarten, J.-F.; Gramlich, V.; Diederich, F. Angew. Chem., Int. Ed. 1998, 37, 1916-1919. (d) Saalfrank, R. W.; Bernt, I.; Uller, E.; Hampel, F. Angew. Chem., Int. Ed. Engl. 1997, 36, 24822483

(5) (a) Fiedler, D.; Leung, D. H.; Bergman, R. G.; Raymond, K. N. Acc. Chem. Res. 2005, 38, 351-360. (b) Yoshizawa, M.; Tamura, M.; Fujita, M. Science 2006, 312, 251-254. (c) Sato, S.; Iida, J.; Suzuki, K.; Kawano, M.; Ozeki, T.; Fujita, M. Science 2006, 313, 1273-1276.

(6) (a) Lee, S. J.; Lin, W. J. Am. Chem. Soc. 2002, 124, 4554-4555. (b) Pak, J. J.; Greaves, J.; McCord, D. J.; Shea, K. J. Organometallics 2002, 21, 3552-3561. (c) Liu, X.; Stern, C. L.; Mirkin, C. A. Organometallics 2002, 21, 1017-1019. (d) Cotton, F. A.; Lin, C.; Murillo, C. A. J. Am Chem. Soc. 2001, 123, 2670-2671.

(7) Lee, S. J.; Hupp, J. T. Coord. Chem. Rev. 2006, 250, 1710-1723.

(8) (a) Bélanger, S.; Hupp, J. T. Angew. Chem. 1999, 38, 2222-2224. (b) Chang, S. H.; Chung, K. B.; Slone, R. V.; Hupp, J. T. Synth. Metals 2001 117, 215-217. (c) Williams, M. E.; Stevenson, K. J.; Massari, A. M.; Hupp, J. T. Anal. Chem. 2000, 72, 3122-3128. (d) Merlau, M. L.; del Pilar Mejia, M.; Nguyen, S. T.; Hupp, J. T. Angew. Chem. 2001, 40, 4239-4242. (e) Mines, G. A.; Tzeng, B.; Stevenson, K. J.; Li, J.; Hupp, J. T. Angew. Chem. 2002, 41, 154-157. (f) Keefe, M. H.; O'Donnell, J. L.; Bailey, R. C.; Nguyen, S. T.; Hupp, J. T. Adv. Mater. 2003, 15, 19361939. (g) Splan, K. E.; Massari, A. M.; Hupp, J. T. J. Phys. Chem. B 2004, 108, 4111-4115. (h) Massari, A. M.; Gurney, R. W.; Schwartz, C. P.; Nguyen, S. T.; Hupp, J. T. Langmuir 2004, 20, 4422-4429. (i) Libera J.; Gurney, R.; Schwartz, C.; Jin, H.; Lee, T.-L.; Nguyen, S. T.; Hupp, J. T.; Bedzyk, M. J. Phys. Chem. B 2005, 109, 1441-1450. (j) Martinson, A. B. F.; Massari, A. M.; Lee, S. J.; Gurney, R. W.; Splan, K. E.; Hupp, J. T.; Nguyen, S. T. J. Electrochem. Soc. 2006, 153, A527-A532.

(9) Miljacic, L.; Sarkisov, L.; Ellis, D. E.; Snurr, R. Q. J. Chem. Phys. 2004, 121, 7228-7236.

(10) Fan, J.; Whitehold, J. A.; Olenyuk, B.; Levin, M. D.; Stang, P. J.; Fleischer, E. B. J. Am. Chem. Soc. 1999, 121, 2741-2752.

(11) The rigid, catalyst-encapsulating, tetrahedral assemblies of Raymond et al. ${ }^{5 \mathrm{a}}$ and the interior-functionalized spherical assemblies of Fujita and coworkers $^{5 b, c}$ can be viewed as alternative solutions to the "torsion problem".

(12) (a) Wilson, G. S.; Anderson, H. L. Chem. Commun. 1999, 1539-1540. (b) Taylor, P. N.; Anderson, H. L. J. Am. Chem. Soc. 1999, 121, 1153811545. (c) Anderson, H. L. Chem. Commun. 1999, 2323-2330.

(13) (a) O’Donnell, J. L. Zuo, X. Goshe, A. J.; Hupp J. T.; Tiede, D. M. J. Am. Chem. Soc. 2007, 129, 1578-1585. (b) Lee, S. J.; Mulfort, K. L.; O'Donnell, J. L.; Zuo, X.; Goshe, A. J.; Wesson, P. J.; Nguyen, S. T.; Hupp, J. T.; Tiede, D. M. Chem. Commun. 2006, 4581-4583. (c) Megyes, T.; Jude, H.; Grosz, T.; Bako, I.; Radnai, T.; Tarkanyi, G.; Palinkas G.; Stang, P. J. J. Am. Chem. Soc. 2005, 127, 10731-10738. (d) Tiede, D M.; Zhang, R. T.; Chen, L. X.; Yu, L. H.; Lindsey, J. S. J. Am. Chem. Soc. 2004, 126, 14054-14062.

(14) Guinier A.; Fournet, G. In Small-Angle Scattering of X-rays; Wiley: New York, 1955. Data were also collected at wide angles (WAXS) as they can yield information about metal-metal separation distances, as well as information about solvent ordering (e.g., refs 13a,b). WAXS data are included as SI. Current work is focused on separating the contributions.

(15) The Stokes-Einstein equation, $D_{\mathrm{s}}=k T / 6 \pi \eta a$, was used to estimate hydrodynamic radii, $a$. In the equation, $k$ is Boltzmann's constant, $T$ is the absolute temperature, and $\eta$ is the viscosity of the medium.

(16) See, for example: Shivanyuk, A.; Rebek, J., Jr. J. Am. Chem. Soc. 2002, 124, 12074-12075. For a contrasting example of narcissistic self-sorting (four- and six-porphyrin assemblies), see ref 12a.

JA077661H 